\section{The lungs at the frontlines of immunity}

Ormase $\mathrm{f}$ all the sites of the body subject to incursion by pathogens, the lungs represent the most challenging immunological dilemma for the host. Not only do the lungs represent the environment most frequently targeted by pathogens, their role as the organ of gas exchange makes their normal functioning critical for health and intolerant of collateral damage. In this special Focus issue, Nature Immunology is proud to present a collection of Reviews covering recent advances in key topics of lung immunology. Accompanying the Focus issue is an animation introducing the lung environment, its main immunological participants and the dysregulated response that occurs during an asthma attack (www.nature.com/ni/multimedia/lung).

Pathogens such as influenza virus and rhinovirus elicit archetypal respiratory infections; influenza virus is also responsible for sporadic and unpredictable pandemics of global importance. Key to the response to such viruses are robust yet well-regulated adaptive immune responses. Chiu and Openshaw review the role of T cells and B cells in the response to viruses, as well as emerging themes such as the specific contribution of follicular helper $\mathrm{T}$ cells and tissue-resident memory $\mathrm{T}$ cells. Although viruses can be directly cytopathic, an important contributor to the lung pathology seen in certain infections, such as infection with influenza virus, is the 'cytokine storm' that arises from a poorly regulated adaptive immune response. Nowhere is this more important than in the delicate tissues of the lungs. Understanding how to initiate well-balanced adaptive immunity will be essential for the development of effective vaccines.

In addition to housing an extensive retinue of cells of the adaptive immune system, the lungs have other critical defensive abilities provided by the respiratory epithelial cells. Whitsett and Alenghat describe how the respiratory epithelium juggles its role as the surface of gaseous exchange with its ability to actively combat infectious agents and harmful particulate matter. On its most basic level, the epithelium represents a physical barrier that produces mucus, which entangles and sweeps away damaging agents via the action of the mucus 'escalator'. However, even surfactant proteins, which are involved mainly in diminishing surface tension, 'moonlight' as antimicrobial molecules and are able to opsonise bacteria. The respiratory epithelium is also able to directly sense pathogens and respond via the release of antimicrobial peptides or signal escalation of the immune response through their production of the cytokines TSLP, IL-25 and IL-33. Collectively, these innate processes are usually able to maintain near-sterility of the lungs without the intervention of 'conventional' cells of the immune system.

Kopf, Schneider and Nobs survey the other critical populations of cells of the innate immune system in the lungs, including dendritic cells and macrophages. As a measure of their importance, alveolar macrophages in the lower respiratory tract make up by far the largest population of leukocytes in the steady state. Not only do these cells ingest microbes and damaging particles but also, as antigen-presenting cells, dendritic cells sample the lung lumen and, along with respiratory epithelial cells, initiate and set the tone of immune responses. The authors also shed light on the origin and development of these populations, which have been hitherto somewhat mysterious.

Finally, a pair of Reviews cover two main diseases of the lungs. Lambrecht and Hammad update the understanding of asthma, the most prevalent allergic disease of the lungs. Although it is conventionally considered a classic type 2 immune disease, the authors emphasize the fact that asthma is extraordinarily heterogeneous, encompassing also neutrophil-, $\mathrm{T}_{\mathrm{H}} 9$ - and $\mathrm{T}_{\mathrm{H}} 17$-dependent forms. This diversity will doubtless represent a challenge for the feasibility of a single effective therapy. Finally, Orme, Robinson and Cooper discuss that most ancient of human infectious diseases, Mycobacteria tuberculosis. Over more than 70,000 years of coevolution with its human host, $M$. tuberculosis has honed its ability to manipulate immune responses. Not only is M. tuberculosis able to avoid elimination, but also its manipulations actually redirect the immune system to maximize the chances of transmission.

Nature Immunology hopes that this collection of Reviews and animation will help spur further work into the understanding of this important field. We thank Janssen Pharmaceutical Companies of Johnson \& Johnson for their financial support in producing this special Focus on the immunology of the lung and its accompanying animation. Nature Immunology is solely responsible for the content of these pages and the animation.

\section{nature immunology}

EDITORIAL \& PRODUCTION OFFICE

75 Varick Street, Fl 9, New York, NY 10013

1917

T: (212) 7269207 Email: immunology@

us.nature.com

www.nature.com/natureimmunology

Chief Editor Jamie D. K. Wilson

Senior Editors Laurie A. Dempsey, Zoltan

Fehervari, Ioana Visan

Fehervari, Ioana Visan
Statistical Advisor Theresa Hyslop

Statistical Advisor Theresa Hy
Copy Editor Jennifer Fosmire

Managing Production Editor Renee Lucas

Senior Production Editor Matt Hansen

Production Editor Jamel Wooten

Senior Illustrator Katie Vicari

Illustrator Marina Corral Spence

Editorial Assistant Lisa Morris

Editor-in-Chief, Nature Publications Philip

Campbell

Executive Editor Kalyani Narasimhan

Nature Editorial Director Ritu Dhand

CUSTOMER SERVICE www.nature.com/help

PERSONAL SUBSCRIPTIONS subscriptions@

nature.com

REPRINTS www.nature.com/reprints

For author and commercial reprints.

ADVERTISING \& SPONSORSHIP www.nature.

com/advertising

Display Advertising

US/Canada: display@us.nature.com

Europe: display@nature.com

Asia: nature@natureasia.com

Sponsorship: sponsorship@nature.com

Nature Jobs: naturejobs@nature.com

SITE LICENSES www.nature.com/libraries/

site licenses/index.html

Americas: T: (888) 3316288 institutions@

us.nature.com

Asia/Pacific: T: 81332678769 institutions@

natureasia.com

Australia/New Zealand: T: 61398251160

nature@macmillan.com.au

Europe/ROW: T: 442078434759 institutions@

nature.com

India: T: 91124 2881054/55 npgindia@nature.

com

PRESS OFFICE press@nature.com

MARKETING marketing@nature.com

MANAGEMENT OFFICES

NPG London

The Macmillan Building, 4 Crinan Street,

London N1 9XW T: 442078334000

NPG New York

75 Varick Street, Fl 9, New York, NY 10013

1917 T: (212) 7269200

NPG Nature Asia-Pacific

Chiyoda Building, 2-37 Ichigayatamachi,

Shinjuku-ku, Tokyo 162-0843 T: 81332678751

A list of other NPG offices can be found at

www.nature.com/npg_/contact/offices.html 